\title{
Modification of oxidative status in Plasmodium berghei-infected erythrocytes by E-2-chloro-8-methyl-3-[(4'-methoxy-1'-indanoyl)- 2'-methyliden]-quinoline compared to chloroquine
}

\author{
Juan Rodrigues ${ }^{1 /+}$, Jaime Charris ${ }^{2}$, José Domínguez ${ }^{2}$, Jorge Ángel ${ }^{3}$, Neira Gamboa ${ }^{1}$ \\ ${ }^{1}$ Unidad de Bioquímica 2Unidad de Síntesis Orgánica, Facultad de Farmacia, Universidad Central de Venezuela, Apartado 47206, \\ Los Chaguaramos, Caracas 1041-A, Venezuela Laboratorio de Síntesis Orgánica y Diseño de Fármacos, Departamento de Química, \\ Facultad Experimental de Ciencias, La Universidad del Zulia, Maracaibo, Venezuela
}

E-2-chloro-8-methyl-3-[(4'-methoxy-1'-indanoyl)-2'-methyliden]-quinoline (IQ) is a new quinoline derivative which has been reported as a haemoglobin degradation and $\beta$-haematin formation inhibitor. The haemoglobin proteolysis induced by Plasmodium parasites represents a source of amino acids and haeme, leading to oxidative stress in infected cells. In this paper, we evaluated oxidative status in Plasmodium berghei-infected erythrocytes in the presence of IQ using chloroquine (CQ) as a control. After haemolysis, superoxide dismutase (SOD), catalase, glutathione cycle and $\mathrm{NADPH}+\mathrm{H}^{+}$-dependent dehydrogenase enzyme activities were investigated. Lipid peroxidation was also assayed to evaluate lipid damage. The results showed that the overall activities of glucose-6-phosphate dehydrogenase and 6-phosphogluconate dehydrogenase were significantly diminished by IQ (by 53.5\% and 100\%, respectively). Glutathione peroxidase activity was also lowered (31\%) in conjunction with a higher GSSG/GSH ratio. As a compensatory response, overall SOD activity increased and lipid peroxidation decreased, protecting the cells from the haemolysis caused by the infection. CQ shared most of the effects showed by IQ; however it was able to inhibit the activity of isocitrate dehydrogenase and glutathione-S-transferase. In conclusion, IQ could be a candidate for further studies in malaria research interfering with the oxidative status in Plasmodium berghei infection.

Key words: malaria - quinoline - oxidative stress - haemoglobin degradation

Haemoglobin proteolysis in intraerythrocytic malaria parasites is a biochemical event which occurs in the acidic digestive vacuole and is mediated by a group of proteases in order to provide free amino acids necessary for protein synthesis (Goldberg et al. 1990, Gamboa \& Rosenthal 1996). In this process, the oxidant haeme group is separated from the globin chains, a process in which $\mathrm{Fe}^{+2}$ is oxidised to $\mathrm{Fe}^{+3}$ and the electrons produced react with molecular oxygen to form oxygen radicals (Mohan et al. 1992a, Atamna \& Ginsburg 1993, Ginsburg \& Atamna 1994, Postma et al. 1996, Francis et al. 1997) Parasites try to protect themselves from the deleterious effect of these free haeme groups by crystallising part of the haeme moieties into an insoluble non-toxic pigment called haemozoin or ß-haematin (Bendrat et al. 1995, Francis et al. 1997). The remaining haeme is detoxified by GSH-dependent degradation. In this context, intraerythrocytic glutathione plays a major role in detoxifying free haeme moieties together with antioxidant enzymes such as superoxide dismutase (SOD) and glutathione peroxidise (GPx) (Atamna \& Ginsburg 2005). An alternative mechanism of haeme detoxification was

Financial support: Consejo de Desarrollo Científico y Humanístico, Universidad Central de Venezuela (PG-CDCH-06.30.5125-2007)

+ Corresponding author: juanricardorodrigues@yahoo.es

Received 10 February 2009

Accepted 18 August 2009 proposed by Loria et al. (1999), who showed that haemoglobin oxidises spontaneously due to the acidic environment of the digestive vacuole, producing superoxide anions. This oxygen radical formation follows the production of $\mathrm{H}_{2} \mathrm{O}_{2}$ and the destruction of the porphyrin ring of the toxic haeme molecule. Plasmodium parasites utilise both the host's as well as their own antioxidant systems to avoid a creation of a pro-oxidative environment and the development of oxidative stress (Ginsburg \& Atamna 1994, Mylonas \& Kouretas 1999).

A series of E-2-quinolinylbenzocycloalcanones have demonstrated antimalarial activity in vivo and in vitro, inhibiting haemoglobin degradation and $\beta$-haematin synthesis. E-2-chloro-8-methyl-3-[(4'-methoxy1'-indanoyl)-2'-methyliden]-quinoline (IQ) proved to be the best compound tested. This compound was able to decrease parasitaemia levels and increase post-infection survival in Plasmodium berghei-infected mice (Charris et al. 2005). On the other hand, some quinoline compounds currently in use exert their activities by increasing oxidative stress in the parasitised erythrocyte. For example, chloroquine (CQ) functions by preventing haeme crystallisation. Additionally, the activity of this drug can be enhanced by depletion of reduced glutathione. Primaquine metabolites induce substantial oxidative stress; the endoperoxide artemisinin is thought to react with haeme moieties, forming cytotoxic radicals (Becker et al. 2004).

In this context, taking into consideration the relationship between haemoglobin degradation and oxidative stress in infected cells as well as the search for potential 
antimalarial compounds with new pharmacological targets, we have evaluated the ability of IQ to modify the oxidative status of $P$. berghei-infected red blood cells.

\section{MATERIALS AND METHODS}

Synthesis of IQ - The compound was synthesised by a base-catalysed Claisen-Schmidt condensation according to Charris et al. (2005). In short, a mixture of the 2-chloro-3-formylquinoline $(1 \mathrm{mmol}), 4$-methoxy-1-indanone $(1 \mathrm{mmol})$ and sodium methoxide (catalytic) in methanol $(8 \mathrm{~mL})$ was stirred at RT overnight. Water was added and the resulting precipitate was collected via filtration, washed with water and recrystallised using ethyl acetate. It is important to mention that ${ }^{1} \mathrm{H}$ NMR spectra of compounds belonging to this family showed that the protons of the $\beta$ and $3^{\prime}$ positions absorbed as a triplet around 8.1 $\mathrm{ppm}$ and a doublet around $3.8 \mathrm{ppm}$, respectively, with coupling constants $J$ ranging $0.9-1.2 \mathrm{~Hz}$, clearly indicating the appearance of allylic coupling among these positions. Additional support for these structures was obtained from ${ }^{13} \mathrm{C}$ NMR. The main shift of carbonyl carbons has a slight variation at $192 \mathrm{ppm}$ in the indanone structure. The enhancement in the $\mathrm{CO}$ shift is due to a moderate polarisation, resulting from the localisation of the $\mathrm{CO}$ bond in the non planar enone moiety.

Experimental host and strain maintenance - Male albino mice (BALB/c, 18-22 g) received a commercial pellet diet and were housed under conditions approved by the Ethical Committee, School of Pharmacy, Central University of Venezuela. P. berghei was used for infections. Mice were infected intraperitoneally with $10^{7}$ infected erythrocytes. Blood samples were removed when the animals reached $25 \%$ parasitaemia and they were diluted in phosphate buffer solution (PBS $10 \mathrm{mM}, \mathrm{pH} 7.4$, $0.1 \mathrm{~mL}$ ). Parasitaemia was monitored by microscopic examination of Giemsa stained smears.

Incubation of erythrocytes with $I Q-1 \times 10^{9}$ noninfected erythrocytes and $P$. berghei-infected erythrocytes from mice (2-3\% parasitaemia and $4 \%$ haematocrit) were incubated in RPMI 1640 medium ( $\mathrm{pH} 7.3$ ) supplemented with $20 \%$ foetal calf serum in presence of IQ or CQ (large-scale cultures) $\left(10 \mu \mathrm{M}, 24 \mathrm{~h} \times 37^{\circ} \mathrm{C}\right.$, $10 \% \mathrm{O}_{2}, 5 \% \mathrm{CO}_{2}, 85 \% \mathrm{~N}_{2}$ gas mixture) (Janse \& Waters 1995). After $24 \mathrm{~h}$ of culture, non-treated infected erythrocytes mostly developed to the schizont stage, while the growth of treated (IQ or CQ), infected erythrocytes was arrested. Samples were centrifuged (5000 $\mathrm{g}$ x $10 \mathrm{~min} \mathrm{x}$ $4^{\circ} \mathrm{C}$ ), washed with saline solution and haemolysed.

Activities of SOD and catalase (CAT) - For SOD activity determination, samples were haemolysed with 0.4 vol of chloroform/ethanol (1.5:1) and activity was measured according to McCord and Fridovich (1969), which tracks the reduction of cytochrome $\mathrm{C}$ at $550 \mathrm{~nm}$. For CAT activity determination, samples were haemolysed with $4 \mathrm{vol}$ of chilled water and diluted 1:500 with phosphate buffer ( $\mathrm{pH}$ 7.0) and activity was measured according to Aebi (1984), which tracks the reduction of $\mathrm{H}_{2} \mathrm{O}_{2}(30 \mathrm{mM})$ at $240 \mathrm{~nm}$. The results were expressed as the percentage of decrease in activity compared to non-infected and non-treated erythrocytes (control cells).
Activities of dehydrogenase enzymes - To determine the activities of glucose-6-phosphate dehydrogenase (G6PD), 6-phosphogluconate dehydrogenase (6PGD) and isocitrate dehydrogenase (ID), samples were lysed (1:10) with stabilised solution $(5 \mu \mathrm{L}$ of $\beta$-mercaptoethanol, $1 \mathrm{~mL}$ of EDTA $10 \%$ and water to $100 \mathrm{~mL}, \mathrm{pH}$ 7.0). Measurements were determined according to Bergmeyer et al. (1974), Bernt and Bergmeyer (1974) and King (1974), respectively, which track the oxidation of NADPH $+\mathrm{H}^{+}$ at $340 \mathrm{~nm}$. The results were expressed as percentage of activity compared to non-infected and non-treated erythrocytes (control cells).

Glutathione cycle determinations - Reduced and oxidised glutathione (GSH, GSSG) from erythrocytes were detected according to a modification of Tietze (1969). In short, samples were lysed with stabilised solution $(1: 10)$ and $1 \mathrm{vol}$ was added to 7 vol of a mixture which contained phosphate buffer, $10 \mathrm{mM} / \mathrm{NADPH}$ $+\mathrm{H}^{+}(0.2 \mathrm{mM} \mathrm{pH} 7.5)$ and $25 \mathrm{uL}$ of dinitro-benzene (DTNB, $0.6 \mathrm{mM}$ ). The mixture was completed with 30 $\mathrm{uL}$ of buffer phosphate $10 \mathrm{mM}, \mathrm{pH}$ 7.0. To measure GSH levels, the increase in optical density at $412 \mathrm{~nm}$ was recorded, representing the formation of the reduced product, thionitrobenzene. GSSG levels were determined after the addition of glutathione reductase $(10 \mu \mathrm{g} / \mathrm{mL})$ to the samples. To determine GPx activity, samples were lysed with stabilised solution (1:10) and measurements were taken according to Paglia and Valentine (1967) with a modification made by Flohé and Günzler (1984), which registers NADPH $+\mathrm{H}^{+}$oxidation at $340 \mathrm{~nm}$. For glutathione- $S$-transferase (GST) activity, samples were haemolysed with stabilised solution (1:10) and measurements were taken according to Habig et al. (1974), which tracks the conjugation of 1-Cl-2,4-dinitro benzene with reduced glutathione at $340 \mathrm{~nm}$. The content of reduced and oxidised glutathione was expressed as the ratio of GSSG/GSH. The activities of GPx and GST were expressed as units of enzyme $/ \mathrm{mg}$.

Determination of erythrocyte lipid peroxidation - To obtain membrane samples, erythrocytes were lysed by treatment with phosphate buffer $(5 \mathrm{mM}, \mathrm{pH}=7.4)$ at $4^{\circ} \mathrm{C}$ (1:10). The haemolysate obtained was centrifuged (20000 $g \times 10 \mathrm{~min}$ at $4^{\circ} \mathrm{C}$ ). Membrane pellets were washed three times with saline solution.

Erythrocyte lipid peroxidation was determined by measuring thiobarbituric acid (TBA) reactivity according to Buege and Aust (1978). In short, membrane samples were mixed with phosphoric acid $10 \% \mathrm{P} / \mathrm{V}$ in $0.1 \mathrm{~N}$ $\mathrm{HCl}(1: 6)$ and TBA $(0.6 \% \mathrm{P} / \mathrm{V}$ in $0.1 \mathrm{~N} \mathrm{HCl})(1: 2)$. Samples were incubated in boiling water for $45 \mathrm{~min}$. Malondyaldehyde (MDA), an end product of fatty acid peroxidation, can react with TBA to form a coloured complex that has a maximum absorbance at $532 \mathrm{~nm}$. Results were expressed as $\mu \mathrm{mol}$ of MDA $/ \mathrm{mg}$.

Protein levels were determined according to Lowry et al. (1951). Data was presented as the average of four independent experiments $(n=4)$ and tested for statistical significance using unpaired $t$-tests for specific group comparisons assuming 95\% confidence limits using GraphPad Prism 4.02 software. 
Ethics - Mice were housed under conditions approved by the Ethical Committee, School of Pharmacy, Central University of Venezuela.

\section{RESULTS}

The parameters of IQ purity and structure confirmation were as follows: yield $90 \%$; m.p. $208-210^{\circ} \mathrm{C}$; IR (KBr) cm-1: 1705 (CO). 1H NMR CDCl3: $d 2.75$ (s, 3H. CH3), 3.88 (d, 2H, H3', J: $1.92 \mathrm{~Hz}$ ), 3.93 (s, 3H, OCH3), 7.07 (d, 1H, H5', J:7.92 Hz), 7.39 (t, 1H, H6, J: 7.67 Hz), 7.47 (m, 1H, H6'), $7.51\left(\mathrm{~m}, 1 \mathrm{H}, \mathrm{H} 7^{\prime}\right), 7.59$ (d, 1H, H7, J:6.68 Hz), 7.74 (d, 1H, H5, J: $8.16 \mathrm{~Hz}$ ), 8.03 (t, 1H, Hv, J: $1.90 \mathrm{~Hz}$ ), 8.39 (s, 1H, H4). 13C NMR: 17.42, 28.74, 55.63, $115.69,116.39,126.09,126.95,127.75,127.38,128.63$, $128.71,131.61,136.81,138.14,138.38,139.30,146.46$, 150.29, 156.70, 193.40. Anal: $\mathrm{C}_{21} \mathrm{H}_{16} \mathrm{NO}_{2} \mathrm{Cl}: \mathrm{C}, 72.10 ; \mathrm{H}$, 4.61; N, 4.01. Found: C, 71.97; H, 4.39; N, 3.89\%.

Defence against oxidative stress represents a very important route for the detoxification of free radicals in infected erythrocytes. Results of experiments on the main antioxidant systems in presence of IQ (Fig. 1) and control CQ are expressed in Figs 2, 3 and Table.

Infection of erythrocytes with $P$. berghei leads to important decreases in the first line of oxidative defence. SOD and CAT activities diminished due to the infection, which could be responsible for the oxidative stress observed in these cells, while treatment with IQ or CQ prevented some loss of activity compared to untreated, infected cells (Fig. 2).

The activities of NADPH $+\mathrm{H}^{+}$-dependent dehydrogenases were also effected, showing significant increases in G6PD, 6PGD and ID in infected, untreated erythrocytes (Fig. 3). Treatment with IQ resulted in a decrease in overall activity for the first two enzymes, which are responsible for the proper functioning of the hexosemonophosphate shunt. CQ-treated, infected erythrocytes also showed significant inhibition in the overall activity of these enzymes as well as in ID activity (Fig. 3).

The GSSG/GSH ratio was increased due to infection (Table), which indicates that the oxidised form is prevalent. In presence of IQ and CQ, this ratio increased significantly compared to untreated and infected erythrocytes. Infection did not change the activity of GPx significantly. However, it increased the overall activity of GST, while CQ decreased the activity of this enzyme.

$P$. berghei infection promotes oxidative stress in infected cells. This was corroborated by higher levels of lipid peroxidation. IQ and CQ were able to decrease lipid damage in infected cells, protecting the host from the deleterious effects of oxidative burst on membranes (Fig. 4).

\section{DISCUSSION}

Haemoglobin degradation by Plasmodium parasites produces active redox products, free haeme and $\mathrm{H}_{2} \mathrm{O}_{2}$, leading to oxidative stress in infected cells. However, the parasite utilises an efficient enzymatic antioxidant system including SOD, CAT, glutathione cycle and dehydrogenase enzymes to avoid the deleterious effects of these redox products. Elements of this antioxidant system could constitute potential targets in the search of new antimalarial compounds.

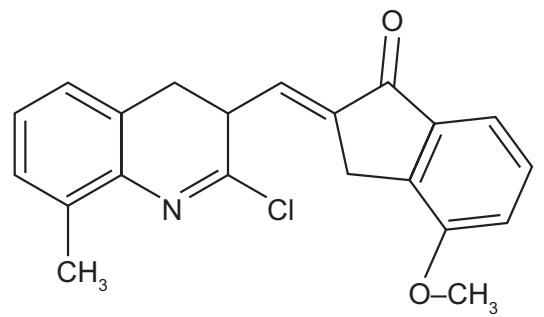

Fig. 1: chemical structure of E-2-chloro-8-methyl-3-[(4'-methoxy-1'indanoyl)-2'-methyliden]-quinoline.

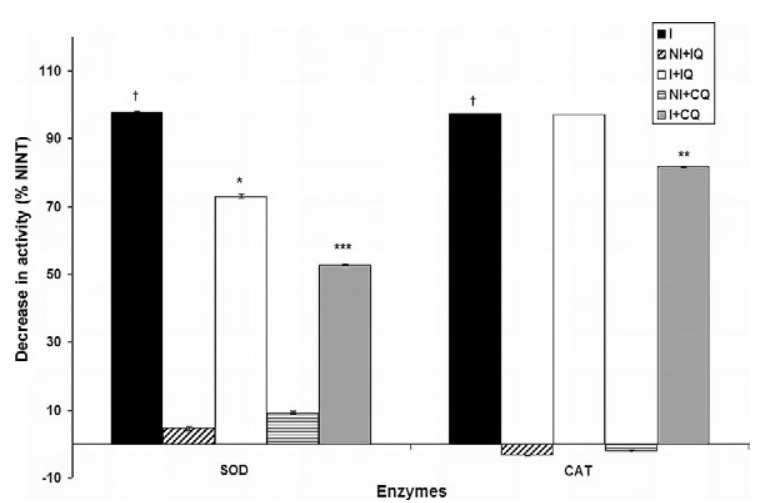

Fig. 2: effect of 2-chloro-8-methyl-3-[(4'-methoxy-1'-indanoyl)-2'methyliden]-quinoline (IQ) and chloroquine (CQ) on the first line of antioxidant enzymes. Results are expressed as the mean \pm SEM of the decrease in the percentage of activity compared to non-infected and non-treated erythrocytes (NINT, basal line). CAT: catalase; I: infected erythrocytes; NI: non-infected erythrocytes; SOD: superoxide dismutase; $\dagger: \mathrm{p}<0.001$ compared to NINT; *: $\mathrm{p}<0.05 ; * * \mathrm{p}<0.01$; $* * *: p<0.001$ compared to $I(n=4)$.

Several antimalarial drugs, such as the endoperoxide antimalarials, seem to act by interfering with the oxidative status of erythrocytes during infection (Ittarat et al. 2003). Indeed, part of the biological activity of CQ results from the augmentation of oxidative stress within the parasites (Toler et al. 2006). This drug leads to increases in the number of oxidised proteins as the intraerythrocytic cycle progresses to mature stages (Radfar et al. 2008). Additionally, CQ treatment mediated oxidative stress in the host; this effect was exacerbated in Plasmodium falciparum infected patients administered with the drug (Farombi et al. 2003).

A group of E-2-quinolinylbenzocycloalcanones have demonstrated antimalarial activity in vivo. Particular attention has been paid to the compound IQ, which was shown to be able to reduce and delay the progression of malaria, decreasing the parasitaemia level by $24 \%$ compared to non-treated mice (control) and increasing survival rate up to 12 days over controls. This compound inhibited haemoglobin proteolysis and B-haematin formation in vitro, suggesting a possible mechanism similar to that of CQ for its antimalarial activity (Charris et al. 2005).

In this paper, we demonstrated that this compound, which is a quinoline-related structure like CQ, was able 


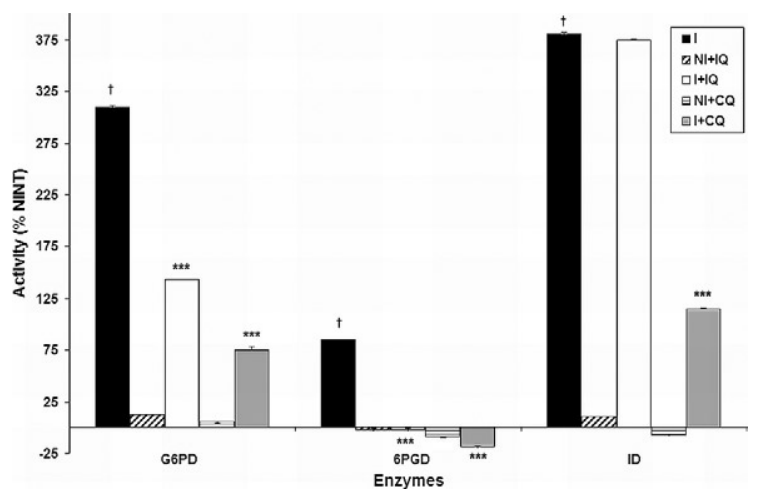

Fig. 3: effect of E-2-chloro-8-methyl-3-[(4'-methoxy-1'-indanoyl)2'-methyliden]-quinoline (IQ) and chloroquine (CQ) on $\mathrm{NADPH}+\mathrm{H}^{+}$ -dependent dehydrogenase enzymes. Results are expressed as the mean \pm SEM of the percentage of activity compared to non-infected and non-treated erythrocytes (NINT, basal line). G6PD: glucose6-phosphate dehydrogenase; I: infected erythrocytes; ID: isocitrate dehydrogenase; NI: non-infected erythrocytes; 6PGD: 6-phosphogluconate dehydrogenase; $\uparrow: \mathrm{p}<0.001$ compared to NINT; $* * *: \mathrm{p}<0.001$ compared to $I(n=4)$.

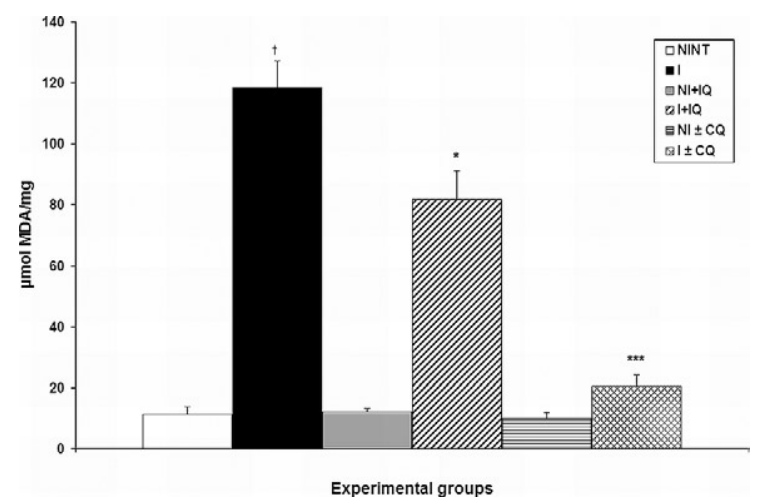

Fig. 4: effect of E-2-chloro-8-methyl-3-[(4'-methoxy-1'-indanoyl)-2'methyliden]-quinoline (IQ) and chloroquine (CQ) on the lipid peroxidation. Results are expressed as the mean \pm SEM of malondialdehyde levels (MDA). I: infected erythrocytes; NI: non-infected erythrocytes; NINT: non-infected and non treated erythrocytes; $\uparrow$ : $\mathrm{p}<0.001$ compared to NINT; *: $\mathrm{p}<0.05 ; * * * \mathrm{p}<0.001$ compared to $\mathrm{I}(\mathrm{n}=4)$. to decrease the hexose-monophosphate shunt in infected erythrocytes, because the overall activity of G6PD and 6PGD were diminished. These results should be added to the known antimalarial properties of this compound and show that these enzymes could represent new targets for antimalarial chemotherapy, as has previously been demonstrated for some antimalarials against purified G6PD (Cotton \& Sutorious 1971). The disruption in this system could produce lower levels of $\mathrm{NADPH}+\mathrm{H}^{+}$, which would make the cells more sensitive to oxidative stress because the glutathione cycle would be compromised due to its dependence on NA$\mathrm{DPH}+\mathrm{H}^{+}$produced by the pentose-phosphate pathway. CQ shared these effects on the dehydrogenase enzymes and also inhibited the overall ID activity in infected cells; these results are in agreement with previous studies which demonstrated inhibitory actions of this quinoline derivative on some of these enzymes (Jarzyna et al. 2001, Sahni et al. 2007) to prevent a general production of $\mathrm{NADPH}+\mathrm{H}^{+}$in infected erythrocytes.

On the other hand, the GSSG/GSH ratio was higher in quinoline-treated infected cells compared to untreated infected erythrocytes, which could be a consequence of the rise in oxidant species in infected cells treated with the compounds. Indeed, the overall activity of GPx was decreased in infected cells treated with each of the quinolines tested. This was also confirmed in malaria patients treated with CQ (Farombi et al. 2003), an effect that could be attributable to the GSSG/GSH increase and to compromised activity of the hexose-monophosphate shunt. The activity of GST increased due to the infection. However, in contrast to a previous report which showed that another cycloalcanone inhibited erythrocyte GST, no changes were observed when the cells were incubated with IQ (Palmen \& Evelo 1998). Our results showed that the effects of IQ on the glutathione system were shared by CQ. However, this antimalarial drug also inhibited the overall activity of GST, which could be due to inhibition of the enzyme by CQ-haeme complex formation (Srivastava et al. 1999). In this context, quinoline compounds act on erythrocytes parasitised by a sensitive $P$. berghei strain, inducing a dramatic decrease in

TABLE

Effect of 2-chloro-8-methyl-3-[(4'-methoxy-1'-indanoyl)-2'-methyliden]-quinoline (IQ) and chloroquine (CQ) on the glutathione system

\begin{tabular}{lccc}
\hline Treatment & GSSG/GSH & GPx $\left(\mathrm{U} / \mathrm{mg}\right.$ prot x10 $\left.0^{-6}\right)$ & GST $\left(\mathrm{U} / \mathrm{mg}\right.$ prot x10 $\left.0^{-3}\right)$ \\
\hline NINT & $23.83 \pm 0.93$ & $21.08 \pm 0.52$ & $40.37 \pm 2.76$ \\
I & $33.19 \pm 0.51^{a}$ & $18.39 \pm 1.6$ & $59.39 \pm 6.1^{a}$ \\
NI + IQ & $21.48 \pm 0.94$ & $22.86 \pm 0.96$ & $42.14 \pm 4.26$ \\
I + IQ & $61.15 \pm 0.29^{c}$ & $12.69 \pm 0.67^{c}$ & $58.05 \pm 6.7$ \\
NI + CQ & $24.08 \pm 0.67$ & $22.74 \pm 0.67$ & $44.65 \pm 5.36$ \\
I + CQ & $62.81 \pm 0.82^{c}$ & $14.32 \pm 0.54^{c}$ & $23.36 \pm 0.17^{b}$ \\
\hline
\end{tabular}

results are expressed as the mean \pm SEM. $a: \mathrm{p}<0.05$ compared to non-infected and non-treated erythrocytes (NINT); $b: \mathrm{p}<$ 0.01; $c$ : $\mathrm{p}<0.05$ compared to infected erythrocytes (I) ( $\mathrm{n}=4)$; GPx: glutathione peroxidase; GST: glutathione-S-transferase; GSH: reduced glutathione; GSSG: oxidized glutathione; NI: non-infected erythrocytes. 
intraerythrocytic reduced glutathione (Bhatia \& Charet 1984). This reduction and the decrease in the overall activity of the NADPH $+\mathrm{H}^{+}$-dependent dehydrogenases would follow a decrease in the overall GPx activity, which, in turn, exacerbates the oxidative stress.

We have shown that SOD activity decreased markedly during infection, which is in agreement with results demonstrated in malaria patients and in $P$. berghei-infected erythrocytes (Farombi et al. 2003, Rodrigues \& Gamboa 2009); however, treatment with IQ and CQ prevented some loss of the activity of this enzyme compared to infected, untreated cells. This event could be produced in response to a compensatory effect due to modification of the glutathione cycle and hexose-monophosphate activity, results that were also reported for the bis-quinoline compound dequalinium (Rodrigues \& Gamboa 2009). Overall CAT activity was also diminished due to the infection, which could also be responsible for the oxidative stress observed in red blood cells infected with Plasmodium (Mohan et al. 1992b). While IQ treatment did not modify the activity of this enzyme in the infected cell population, CQ could reduce the decrease in enzyme activity in infected cells.

Lipid peroxidation was also a consequence of the infection. Oxidative stress promotes lipid damage and, consequently, it may affect the cell membrane (Dondorp et al. 1999). Infected cells treated with IQ or CQ showed lower levels of MDA, a lipid peroxidation marker. This effect could be beneficial, protecting the cells from haemolysis, which results in the development of the anaemia typically observed in malaria patients. This is in agreement with data published on another cycloalcanone, which did not cause lipid peroxidation in erythrocytes (Palmen \& Evelo 1998) as well as data on another quinoline derivative, which also diminished malondialdehyde levels in infected cells (Rodrigues \& Gamboa 2009). Nevertheless, this result is contradictory because both quinoline compounds seem to promote oxidative stress in infected cells. This protective quinoline-mediated decrease in lipid peroxidation effect may be a consequence of other effects in infected cells instead of an effect resulting from oxidative stress. A previous study has demonstrated the ability of CQ to inhibit lipid peroxidation in cell samples (Jackson et al. 1984), possibly due to its effects as a phospholipase-A2 inhibitor. Additionally, Nosál et al. (1995) reported that this compound inhibited arachidonic acid liberation from membrane phospholipids.

On the other hand, both quinolines have reported to inhibit haeme crystallisation (Chong \& Sullivan 2003, Charris et al. 2005). This porphyrin is toxic to cells by way of free radical-dependent mechanisms (Kumar \& Bandyopadhyay 2005). In this context, there is a strong correlation between the effects of these compounds on $\beta$-haematin formation and the inhibition of different enzymes involved in oxidative stress. Free haeme catalyses oxidation, covalent cross-linking and formation of protein aggregates as well as the degradation of small peptides. There is also the possibility of formation of IQ-haeme complexes, as it occurs with CQ in the food vacuole of the parasites (Sullivan et al. 1996), which, by mimicking haeme, stalls all mechanisms of haeme crystallisation, resulting in the death of the malaria parasite. It is likely that the plasmodicidal activity of these compounds results from augmentation of parasite oxidative stress.

In conclusion, we have investigated different effects caused by IQ in P. berghei-infected erythrocytes to evaluate the mechanism of action of this possible antimalarial agent. In the presence of this compound, the overall activity of the hexose-monophosphate shunt in infected erythrocytes was diminished, which could also lead to a decrease in glutathione cycle activity due to compromised levels of NADPH $+\mathrm{H}^{+}$. This effect could prevent some loss of SOD activity related to infection. Lipid peroxidation was also decreased by this compound, which would protect the host from the severe anaemia caused by the infection. Although more molecular studies of drug-receptor interactions are needed, our results suggest that IQ has antimalarial properties with a mechanism of action which involves not just the inhibition of haemoglobin proteolysis and haeme crystallisation but results in a modification of the oxidative status of infected cells; these results were generally recapitulated by CQ. In this context, this compound could be a candidate for further studies as a possible treatment for malaria.

\section{ACKNOWLEDGEMENTS}

To Neuropeptide Laboratory, School of Pharmacy, Central University of Venezuela, for the disposition of the microplate spectrophotometer.

\section{REFERENCES}

Aebi H 1984. Catalase in vitro. Methods Enzymol 103: 121-126.

Atamna H, Ginsburg H 1993. Origin of reactive oxygen species in erythrocytes infected with Plasmodium falciparum. Mol Biochem Parasitol 61: 231-241.

Atamna H, Ginsburg H 2005. Heme degradation in the presence of glutathione. J Biol Chem 27: 24876-24883.

Becker K, Tilley L, Vennerstrom DR, Rogerson S, Ginsburg H 2004. Oxidative stress in malaria parasite-infected erythrocytes: hostparasite interactions. Int J Parasitol 34: 163-189.

Bendrat K, Berger BJ, Cerami A 1995. Haem polymerization in malaria. Nature 378: 138.

Bergmeyer HU, Gawehn K, Grassl M 1974. Glucose-6-phosphate dehydrogenase. In HU Bergmeyer, Methods of enzymatic analysis, Academic Press, New York, p. 458-459.

Bernt E, Bergmeyer HU 1974. Isocitrate dehydrogenase. In HU Bergmeyer, Methods of enzymatic analysis, Academic Press, New York, p. 624-631.

Bhatia Am, Charet P 1984. Action of chloroquine on glutathione metabolism in erythrocytes parasitized by Plasmodium berghei. Ann Parasitol Hum Comp 59: 317-320.

Buege JA, Aust SD 1978. Microsomal lipid peroxidation. Methods Enzymol 52C: 302-310.

Charris J, Domínguez JN, Gamboa N, Rodrigues J, Angel J 2005. Synthesis and antimalarial activity of E-2-quinolinylbenzocycloalcanones. Eur J Med Chem 40: 875-881.

Chong CR, Sullivan DJ Jr 2003. Inhibition of heme crystal growth by antimalarials and other compounds: implications for drug discovery. Biochem Pharmacol 66: 2201-2212. 
Cotton DWK, Sutorius AHM 1971. Inhibiting effect of some antimalarial substances on glucose-6-phosphate dehydrogenase. Nature 233: 197.

Dondorp AM, Angus BJ, Chotivanich K, Silamut K, Ruangveerayuth R, Hardeman MR, Kager PA, Vreeken J, White NJ 1999. Red blood cell deformability as a predictor of anemia in severe falciparum malaria. Am J Trop Med Hyg 60: 733-737.

Farombi EO, Shyntum YY, Emerole GO 2003. Influence of chloroquine treatment and Plasmodium falciparum malaria infection on some enzymatic and non-enzymatic antioxidant defense indices in humans. Drug Chem Toxicol 26: 59-71.

Flohé L, Günzler WA 1984. Assays of glutathione peroxidase. Methods Enzymol 77: 398-404.

Francis SE, Sullivan DJJr, Goldberg DE 1997. Hemoglobin metabolism in the malaria parasite Plasmodium falciparum. Annu Rev Microbiol 51: 97-123.

Gamboa ND, Rosenthal P 1996. Cysteine proteinase inhibitors block early steps in hemoglobin degradation by cultured malaria parasites. Blood 87: 4448-4454.

Ginsburg H, Atamna H 1994. The redox status of malaria-infected erythrocytes: an overview with an emphasis on unresolved problems. Parasite 1: 5-13.

Goldberg DE, Slater AF, Cerami A, Henderson GB 1990. Hemoglobin degradation in the malaria parasite Plasmodium falciparum: an ordered process in a unique organelle. Proc Natl Acad Sci USA 87: 2931-2935.

Habig WH, Pabst MJ, Jakoby WB 1974. Glutathione-S-transferase. The first enzymatic step in mercapturic acid formation. $J$ Biol Chem 249: 7130-7139.

Ittarat W, Sreepian A, Srisarin A, Pathepchotivong K 2003. Effect of dihydroartemisinin on the antioxidant capacity of $P$. falciparuminfected erythrocytes. Southeast Asian J Trop Med Public Health 34: $755-750$.

Jackson MJ, Jones DA, Harris EJ 1984. Inhibition of lipid peroxidation in muscle homogenates by phospholipase A2 inhibitors. Biosci Rep 5: 581-587.

Janse CJ, Waters AP 1995. Plasmodium berghei: the application of cultivation and purification techniques to molecular studies of malaria parasites. Parasitol Today 11: 138-143.

Jarzyna R, Kiersztan, Lisowa O, Bryla J 2001. The inhibition of gluconeogenesis by chloroquine contributes to its hypoglycaemic action. Eur J Pharmacol 428: 381-388.

King J 1974. 6-Phosphogluconate dehydrogenase. In HU Bergmeyer, Methods of enzymatic analysis, Academic Press, New York, p. 632-635.

Kumar S, Bandyopadhyay U 2005. Free heme toxicity and its detoxification systems in human. Toxicol Lett 157: 175-188.

Loria P, Miller S, Folley M, Tilley L 1999. Inhibition of the peroxidative degradation of haem as the basis of action of chloroquine and other quinoline antimalarials. Biochem J 339: 363-370.
Lowry OH, Rosebrough NJ, Farr AL, Randall R 1951. Protein measurement with the Folin phenol reagent. J Biol Chem 193: 265-275.

McCord JM, Fridovich I 1969. Superoxide dismutase. An enzymic function for erythrocuprein (hemocuprein). J Biol Chem 244: 6049-6053.

Mohan K, Ganguly NK, Dubey ML, Mahajan RC 1992a. Oxidative damage of erythrocyte infected with Plasmodium falciparum. An in vitro study. Ann Hematol 651: 31-134.

Mohan K, Ganguly NK, Dubey ML, Mahajan RC 1992b. Plasmodium falciparum induced perturbations of the erythrocyte antioxidant system. Clin Chim Acta 209: 19-26.

Mylonas C, Kouretas D 1999. Lipid peroxidation and tissue damage. In vivo 13: 295-309.

Nosál R, Jancinová V, Petríková M 1995. Chloroquine inhibits stimulated platelets at the arachidonic acid pathway. Thromb Res 77: 531-542.

Paglia DE, Valentine WN 1967. Studies on the quantitative and qualitative characterization of erythrocyte glutathione peroxidase. $J$ Lab Clin Med 70: 159-164.

Palmen NG, Evelo CT 1998. Oxidative effects in human erythrocytes caused by some oximes and hydroxylamine. Arch Toxicol 72: $270-276$

Postma NS, Mommers EC, Eling WM, Zuidema J 1996. Oxidative stress in malaria: implications for prevention and therapy. Pharm World Sci 18: 121-129.

Radfar A, Diez A, Bautista JM 2008. Chloroquine mediates specific proteome oxidative damage across the erythrocytic cycle of resistant Plasmodium falciparum. Free Radic Biol Med 44: 2034-2042.

Rodrigues JR, Gamboa ND 2009. Effects of dequalinium on the oxidative stress in Plasmodium berghei-infected erythrocytes. Parasitol Res 104: 1491-1496.

Sahni S, Saxena N, Puri S, Dutta G, Pandey V 2007. NADP-specific isocitrate dehydrogenase from the simian malaria parasite Plasmodium knowlesi: partial purification and characterization. J Euk Microbiol 39: 338-342.

Srivastava P, Puri SK, Kambok KK, Pandey VC 1999. GlutathioneS-transferase activity in malarial parasites. Trop Med Int Health 4: $251-254$.

Sullivan DJ Jr, Gluzman IY, Russell DG, Goldberg DE 1996. On the molecular mechanism of chloroquine's antimalarial action. Proc Natl Acad Sci USA 93: 11865-11870.

Tietze F 1969. Enzymatic method for quantitative determination of nanogram amounts of total and oxidized glutathione. Anal Biochem 27: 502-522.

Toler SM, Noe D, Sharma A 2006. Selective enhancement of cellular oxidative stress by chloroquine: implications for the treatment of glioblastoma multiforme. Neurosurg Focus 21: E10. 